\title{
Curcumin inhibits the invasion of lung cancer cells by modulating the PKCo/Nox-2/ROS/ATF-2/MMP-9 signaling pathway
}

\author{
ZHIGANG FAN $^{1,2}$, XIAOYI DUAN ${ }^{3}$, HUI CAI ${ }^{1,4}$, LI WANG $^{1,5}$, MIN LI $^{1}$, JINGKUN QU $^{1}$, \\ WANJUN LI ${ }^{1,6}$, YONGHENG WANG ${ }^{1,7}$ and JIANSHENG WANG ${ }^{1}$ \\ ${ }^{1}$ The Second Department of Thoracic Surgery, The First Affiliated Hospital of Xi'an Jiaotong University, Xi'an; \\ ${ }^{2}$ Department of Oncology, No. 3201 Hospital of Xi'an Jiaotong University, Hanzhong; Departments of ${ }^{3}$ Nuclear Medicine \\ and ${ }^{4}$ Anesthesia, The First Affiliated Hospital of Xi'an Jiaotong University, Xi'an; ${ }^{5}$ Department of Internal Medicine, \\ Hospital of Chang'an University, Xi'an; ${ }^{6}$ Department of Pathology, No. 3201 Hospital of Xi'an Jiaotong University, \\ Hanzhong; ${ }^{7}$ Provincial Hospital of Xi'an Jiaotong University, Xi'an, Shaanxi, P.R. China
}

Received March 11, 2015; Accepted April 21, 2015

DOI: $10.3892 / o r .2015 .4044$

\begin{abstract}
Invasion and metastasis are the major causes of tumor-related mortality in lung cancer. It is believed that curcumin is an effective drug possessing anti-invasive and anti-metastatic activities in the treatment of cancer. However, the specific mechanisms remain unclear. In the present study, we investigated whether the PKC $\alpha /$ Nox-2/ATF-2/MMP-9 signaling pathway is involved in the invasive behavior of lung cancer and whether curcumin could inhibit invasion by modulating this pathway. The cytotoxic effect of curcumin was evaluated by MTT assay and the capacity of invasion was assessed by Transwell assay. siRNA and plasmid transfection techniques were used to study the function of targeted genes. Real-time PCR and western blot analysis were used to evaluate the expression levels of PKC $\alpha$, Nox-2, MMP-9 and the phosphorylation of ATF-2. The results showed that curcumin inhibited the proliferation and invasion of A549 cells in a dose-dependent manner. Overexpression of MMP-9 enhanced the invasion of A549 cells. However, inhibition of MMP-9 by siRNA or curcumin suppressed cell invasion. Moreover, we also demonstrated the catalytic role of PKC $\alpha$ in expression of MMP-9 and cellular invasion in A549 cells, which was dependent on the expression of Nox-2 and phosphorylation of ATF-2. Finally, we also showed that curcumin dose-dependently reduced the expression of PKC $\alpha, \mathrm{P} 47^{\text {phox }}$, Nox-2 and phosphorylated ATF-2, as well as intracellular ROS generation, suggesting the inhibitory effect of curcumin on the activation of the $\mathrm{PKC} \alpha / \mathrm{Nox}-2 / \mathrm{ROS} / \mathrm{ATF}-2$ pathway. In conclusion, the PKCa/Nox-2/ROS/ATF-2/MMP-9 signaling
\end{abstract}

Correspondence to: Dr Jiansheng Wang, The Second Department of Thoracic Surgery, The First Affiliated Hospital of Xi'an Jiaotong University, Xi'an, Shaanxi, P.R. China

E-mail: wangjsh@mail.xjtu.edu.cn

Key words: curcumin, lung cancer, invasion, signaling pathway pathway is activated in lung cancer A549 cells, which could be modulated by curcumin to inhibit cell invasiveness.

\section{Introduction}

As one of the most common malignant diseases of the respiratory system, lung cancer is associated with a 5-year overall survival rate of $15 \%$ and is among the leading causes of cancerrelated deaths worldwide (1). Treatment failure is mainly caused by the high invasive and metastatic potential, which characterizes its high malignant potential (2). It was reported that $\sim 90 \%$ of malignant tumor-related deaths are due to invasion and metastasis, which is also true for lung cancer (3). The mechanisms of invasion of lung cancer are complicated since multiple biological processes such as alterations in gene expression and changes in several signaling pathways are usually involved. Thus, identifying the therapeutic drugs specifically targeting these processes to inhibit the invasiveness of lung cancer is of significant importance.

A zinc-dependent proteinase family, the matrix metalloproteinases (MMPs), are believed to participate in numerous pathological processes due to their activity in extracellular matrix (ECM) degradation (4). MMPs are associated with non-neoplastic diseases including ischemia (5), trauma (6), and neoplastic diseases including glioma (7), and breast (8) and liver cancer (9). It is currently generally accepted that cancer cells invade through tissue by secreting these enzymes. As an important member of the MMPs, MMP-9 overexpression is often detected in various human invasive cancers (10). The regulation of expression of MMP-9 is mediated by multiple activators such as NF- $\mathrm{B}$ (11). The most direct induction of MMP-9 expression is through the activating transcription factor-2 (ATF-2) (12) which further binds to the AP-1 site of the MMP-9 gene promoter to enhance MMP-9 transcription (13). A previous study found that ATF-2 was activated by phosphorylation in a reactive oxygen species (ROS)-dependent manner in fibroblasts and myocytes (14).

1,7-Bis(4-hydroxy-3-methoxyphenol)-1,6-heptadiene-3,5dione, also known as curcumin, is extracted and obtained from the roots of a plant named turmeric (Curcuma longa L.). 
Curcumin's hydrophobic polyphenol molecular structure contributes to its multiple biological functions including its anticancer activity (15). Studies have revealed that curcumin inhibits malignant cell migration, invasion and metastasis by repressing expression of multiple proteins including MMPs $(16,17)$; however, the exact mechanisms require further investigation.

Curcumin reduces excessive production of ROS in mammalian cells which may lead to multiple biological effects (18). A previous study suggested that cellular ROS were generated in an enzymatic reaction catalyzed by NADPH oxidase- 2 (Nox-2) under external stimuli (19). Nox-2 is activated by phosphorylation of its subunit $\mathrm{P} 47^{\text {phox }}$ which was suggested to be phosphorylated by protein kinase $\mathrm{C} \alpha(\mathrm{PKC} \alpha)(20)$. A recent study pointed out that curcumin inhibits phosphorylation of Nox subunits by reducing PKC expression (21).

In this context, we hypothesized a possible mechanism that curcumin inhibits MMP-9 expression in lung cancer cells by inhibiting activation of PKC $\alpha /$ Nox-2/ATF-2 signaling. The results in the present study broaden the knowledge of the mechanisms of the anticancer activity of curcumin, and also provide new clues for the molecular-targeted treatment of malignant diseases.

\section{Materials and methods}

Cell line, culturing and treatment. Human lung cancer cell line A549 was acquired from the Cell Resource Center of the Chinese Academy of Sciences. The cells were cultured in cell culturing flasks (Corning) and maintained in RPMI-1640 culture medium (HyClone) supplemented with fetal bovine serum (FBS, 10\%; HyClone), glutamine ( $2 \mathrm{mmol} / \mathrm{l}$; Sigma) and antibiotics including $100 \mu \mathrm{g} / \mathrm{ml}$ streptomycin and $100 \mathrm{U} / \mathrm{ml}$ penicillin (both from Sigma). Cells were cultured in a cell culture incubator (Thermo) providing a humidified environment with $95 \%$ fresh air and 5\% carbon dioxide. Cells were treated with serially diluted curcumin (Sigma) at various concentrations $(0,15,30$ and $60 \mu \mathrm{mol} / \mathrm{l})$ for $24 \mathrm{~h}$.

Cell viability evaluation. Cell viability of the A549 cells was assessed by colorimetric 3-(4,5-dimethylthiazol-2-yl) 2,5-diphenyltetrazolium bromide (MTT) assay in accordance with standard methods. After an equal number of cells $\left(2 \times 10^{4}\right)$ were plated in a 96-well plate (Corning), the treated cells were washed with sterilized phosphate-buffered saline (PBS; Pioneer) twice, and then incubated with MTT (Sigma) at a final concentration of $5 \mathrm{mg} / \mathrm{ml}$ for $4 \mathrm{~h}$ in an incubator. After PBS washing, the cells were dissolved in dimethyl sulfoxide (DMSO; Sigma). The 450-nm absorbance value was read by a plate reader (Bio-Rad). The cell viability was presented as the inhibition rate, which was expressed as a ratio of the number of the non-viable cells in the experimental wells (cells treated by curcumin) compared to the control wells.

DNA and RNA transfection. Six-well plates were seeded with $5 \times 10^{4}$ cells/well in $2 \mathrm{ml}$ media $24 \mathrm{~h}$ before transfection; the cells were $80-90 \%$ confluent. Cells were transfected with siRNA (100 pmol/well) or plasmid DNA ( $4 \mu \mathrm{g} / \mathrm{well})$ using Lipofectamine 2000 reagent (Life Technologies, Grand Island, NY, USA) according to the manufacturer's instructions. After
$48 \mathrm{~h}$ of transfection, the cells were collected for subsquent experiments. For establishing stable cell lines, the cells were selected using puromycin for 2 weeks. Stable transductants were pooled. All siRNAs and shRNA were purchased from Santa Cruz Biotechnology (Santa Cruz, CA, USA). The pHACE-PKC $\alpha$ WT plasmid (22) was provided by Addgene (Addgene plasmid, 21232).

Cell invasion assay. The invasive ability of the A549 cells was assessed by Transwell assays using the BioCoat Matrigel invasion assay system (BD Biosciences) according to standard protocols. After suspension in serum-free medium, the cells were seeded. The Matrigel was used to coat the upper surface of the Transwell chambers for invasion assay. After a 24-h incubation, the cells that invaded through the membrane were fixed with methanol. The invasion was then observed and evaluated after crystal violet staining under an optical microscopy.

Intracellular ROS detection. The intracellular ROS level in the A549 cells was detected by 2',7'-dichlorofluorescein diacetate (DCFH-DA). The cultured A549 cells were incubated with serum-free RPMI-1640 medium supplemented with DCFH-DA (Beyotime) at a final concentration of $10 \mu \mathrm{mol} / 1$ at $47^{\circ} \mathrm{C}$ for $40 \mathrm{~min}$. Then the fluorescence of DCFH-DA at $530 \mathrm{~nm}$ was detected using the FACSCalibur flow cytometer (BD Biosciences).

Quantitativereal-time PCR. TotalRNA from the A549 cells was isolated by using the RNeasy Mini kit (Invitrogen) according to the manufacturer's instructions. Reverse transcription was performed, and cDNA was synthesized using SuperScript III Reverse Transcriptase (Invitrogen). Quantitative real-time PCR was then performed using SYBR-Green II according to the PrimeScript RT-PCR kit protocol (Takara). The specific primers for each gene (PKC $\alpha$, Nox-2, MMP-9 and $\beta$-actin) were designed and synthesized by Takara. $\beta$-actin was introduced as the internal control. The $2^{-\Delta \Delta \mathrm{Ct}}$ method was used to analyze the relative expression levels for PKC $\alpha$, Nox-2 and MMP-9.

Western blot analysis. The A549 cells in each group were harvested and lysed in RIPA lysis buffering system $(\mathrm{pH}, 7.5$; $40 \mathrm{mmol} / \mathrm{l}$ Tris-HCI, $150 \mathrm{mmol} / \mathrm{l} \mathrm{KCl}, 100 \mathrm{mmol} / \mathrm{l} \mathrm{NaVO}_{3}$, $1 \mathrm{mmol} / \mathrm{l}$ EDTA, $1 \%$ Triton X-100 and $1 \mathrm{mmol} / \mathrm{l} \mathrm{PMSF})$. The concentration of the extracted proteins was determined by the BCA kit (Thermo). The same amount of protein $(50 \mu \mathrm{g})$ from each group was separated by SDS-polyacrylamide gel (8 or $10 \%$ ) vertical electrophoresis and then transferred to PVDF membranes. Defatted milk (5\% in TBST buffer) was used to block the non-specific binding by incubation with the membranes at $37^{\circ} \mathrm{C}$ for $1 \mathrm{~h}$. After washing, the membranes were incubated with specific antibodies against PKC $\alpha$, Nox-2 and P47 $7^{\text {phox }}$ (all from Abcam), p-ATF-2 and ATF-2 (both from Cell Signaling Technology) and MMP-9 and $\beta$-actin (both from Santa Cruz Biotechnology) at $4^{\circ} \mathrm{C}$ for $12 \mathrm{~h}$. After washing, the membranes were then incubated by corresponding horseradish peroxidase secondary antibodies at room temperature for $1 \mathrm{~h}$. Then an enhanced chemiluminescence kit (Amersham) was used to detect the bands. Software Image J was used to perform the densitometric analysis. 
Statistical analysis. Data collected in the present study are expressed as the (mean $\pm \mathrm{SD}$ ). Differences between groups were analyzed using the Student's t-test. $\mathrm{P}<0.05$ was considered to be indicative of a statistically significant result.

\section{Results}

Curcumin inhibits the proliferation and invasion of A549 cells. We first evaluated the effects of curcumin on cancer cell proliferation and invasion. The MTT results showed that curcumin inhibited the proliferation of A549 cells in a dose-dependent manner with a significant anti-proliferative effect $>40 \mu \mathrm{mol} / 1$ (Fig. 1A). As it was considered that the inhibition of metastasis may be attributed to the tumor growth inhibition, the concentrations which inhibit cell growth were excluded to avoid the cytotoxic effect of curcumin on cell invasion. Thus, a concentration range $<40 \mu \mathrm{mol} / 1$ (10, 20 and $30 \mu \mathrm{mol} / 1$ particularly in this study) was chosen for subsequent invasion experiments. Transwell assays demonstrated that curcumin inhibited the invasion of the A549 cells at the above concentrations (Fig. 1B).

Curcumin inhibits the invasion of A549 cells by suppressing the expression of MMP-9. The potential involvement of MMP-9 in cellular invasion was evaluated. MMP-9 was effectively upregulated or downregulated by the pcDNA3.1MMP-9 cDNA plasmid or siRNA (Fig. 2A). As shown in Fig. 2B, cell invasion was significantly increased in the MMP-9-overexpressed cells and reduced in the MMP-9downregulated cells. We further tested the inhibitory effects of curcumin on both the MMP-9 overexpressed and downregulated A549 cells. As expected, curcumin did not inhibit the invasion of the MMP-9-downregulated A549 cells when compared with the controls (Fig. 2C). However, in the MMP-9-overexpressed A549 cells, curcumin still exhibited an inhibitory effect on cell invasion (Fig. 2C). Furthermore, we also demonstrated that curcumin dose-dependently suppressed the expression of MMP-9 in the A549 cells at both the mRNA and protein levels (Fig. 2D and E), supporting the functional role of MMP-9 in curcumin-inhibited lung cancer cell invasion.

Involvement of $P K C \alpha$ in expression of MMP-9 and cell invasion of A549 cells. The PKC $\alpha$ cDNA plasmid (pHACE-PKC $\alpha$ WT) and siRNA were used to establish the PKC $\alpha$ upregulated and downregulated A549 cells (Fig. 3A). Expression of MMP-9 was then evaluated by real-time PCR and western blot analyses. As shown in Fig. 3B, upregulation of PKC $\alpha$ induced expression of MMP-9 and inhibition of PKC $\alpha$ by siRNA suppressed the MMP-9 protein expression. In addition, we assessed the potential roles of PKC $\alpha$ in the cell invasion of A549 cells. When expression of PKC $\alpha$ was inhibited by siRNA, the number of invasive A549 cells was reduced (Fig. 3C). In contrast, overexpression of PKC $\alpha$ increased the invasive ability of the A549 cells (Fig. 3C).

PKC $\alpha$-induced expression of MMP-9 is Nox-2-dependent. Since Nox-2 is one of the downstream molecules of PKC $\alpha(20,21)$, we aimed to ascertain whether Nox-2 is involved in the PKC $\alpha /$ MMP-9 signaling pathway. Specific
A

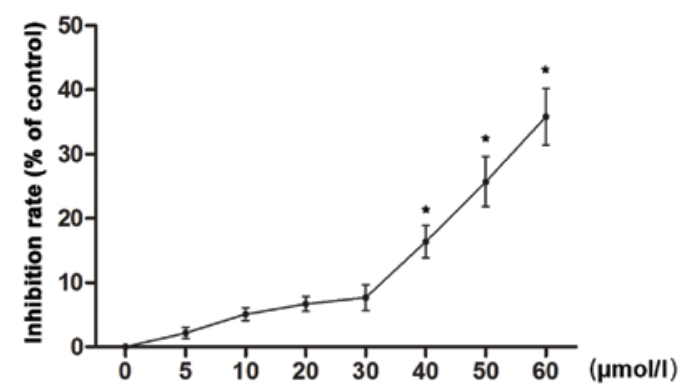

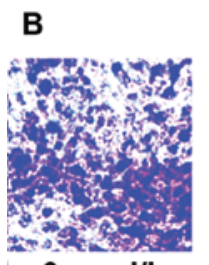

$0 \mu \mathrm{mol} / \mathrm{l}$

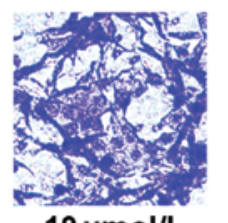

$10 \mu \mathrm{mol} / \mathrm{l}$

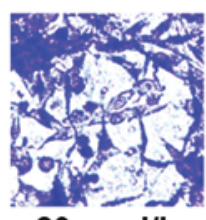

$20 \mu \mathrm{mol} / \mathrm{l}$

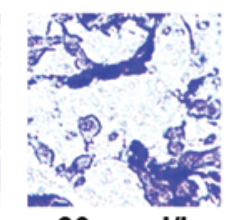

$30 \mu \mathrm{mol} / \mathrm{l}$

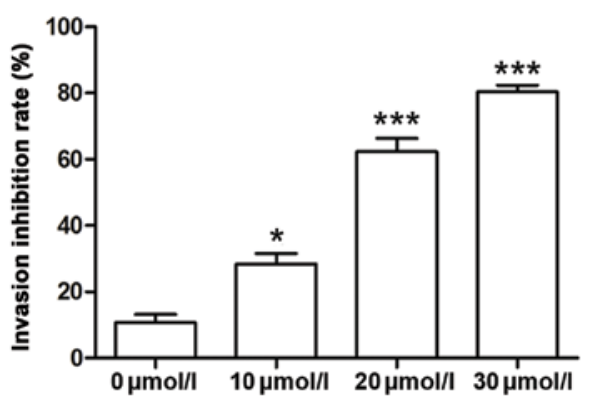

Figure 1. Curcumin inhibits the proliferation and invasion of A549 cells. (A) A549 cells were incubated with curcumin at different concentrations of $0,5,10,20,30,40,50$ and $60 \mu \mathrm{mol} / 1$ for $24 \mathrm{~h}$. The inhibitory effects of curcumin on the proliferation of A549 cells were assessed by MTT assay. The line graph shows the inhibition rate of values represented as mean $\pm \mathrm{SD}$; ${ }^{*} \mathrm{P}<0.05$. (B) The effect of curcumin on cell invasion in the A549 cells was assessed by Transwell assay. Columns indicate the invasion inhibition rate of curcumin on the A549 cells at different concentrations respectively, ${ }^{*} \mathrm{P}<0.05$, ${ }_{* * * *} \mathrm{P}<0.001$.

shRNA was used to establish the stable Nox-2-knockdown A549 cells (Fig. 4A). Expression of MMP-9 was then detected in the Nox-2-knockdown and control cells with or without transfection of the PKC $\alpha$ cDNA plasmid. The results showed that knockdown of Nox-2 markedly inhibited PKC $\alpha$-induced expression of MMP-9 (Fig. 4B). Moreover, we found that overexpression of $\mathrm{PKC} \alpha$ increased the expression of $\mathrm{P} 47^{\text {phox }}$ and Nox-2 (Fig. 4C).

PKC $\alpha$-induced expression of MMP-9 is ATF-2-dependent. We further assessed the potential role of ATF-2 in the PKC $\alpha /$ MMP-9 signaling pathway. Specific shRNA was used to establish stable ATF-2-knockdown A549 cells (Fig. 5A). Expression of MMP-9 was then detected in the ATF-2knockdown and control cells with or without transfection of the PKC $\alpha$ cDNA plasmid. As shown in Fig. 5B, knockdown of ATF-2 markedly inhibited PKC $\alpha$-induced expression of MMP-9. Meanwhile, overexpression of PKC $\alpha$ induced phosphorylation of ATF-2 without affecting the protein level of ATF-2 (Fig. 5C). 
A

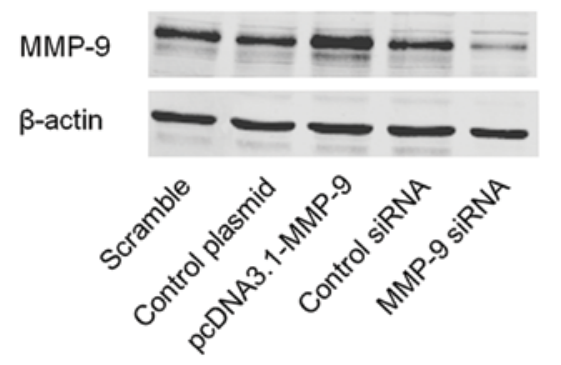

B

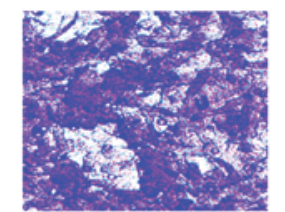

Control plasmid

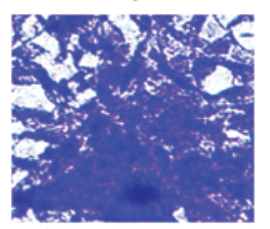

Control siRNA
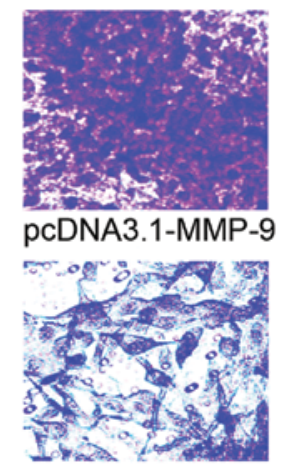

MMP-9 siRNA

C

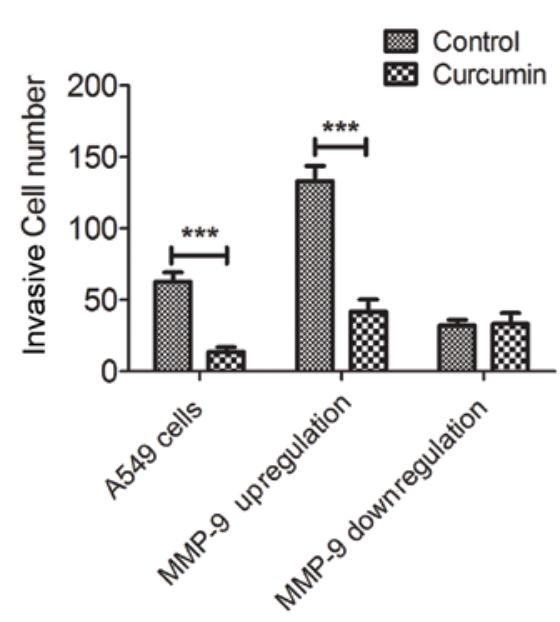

D
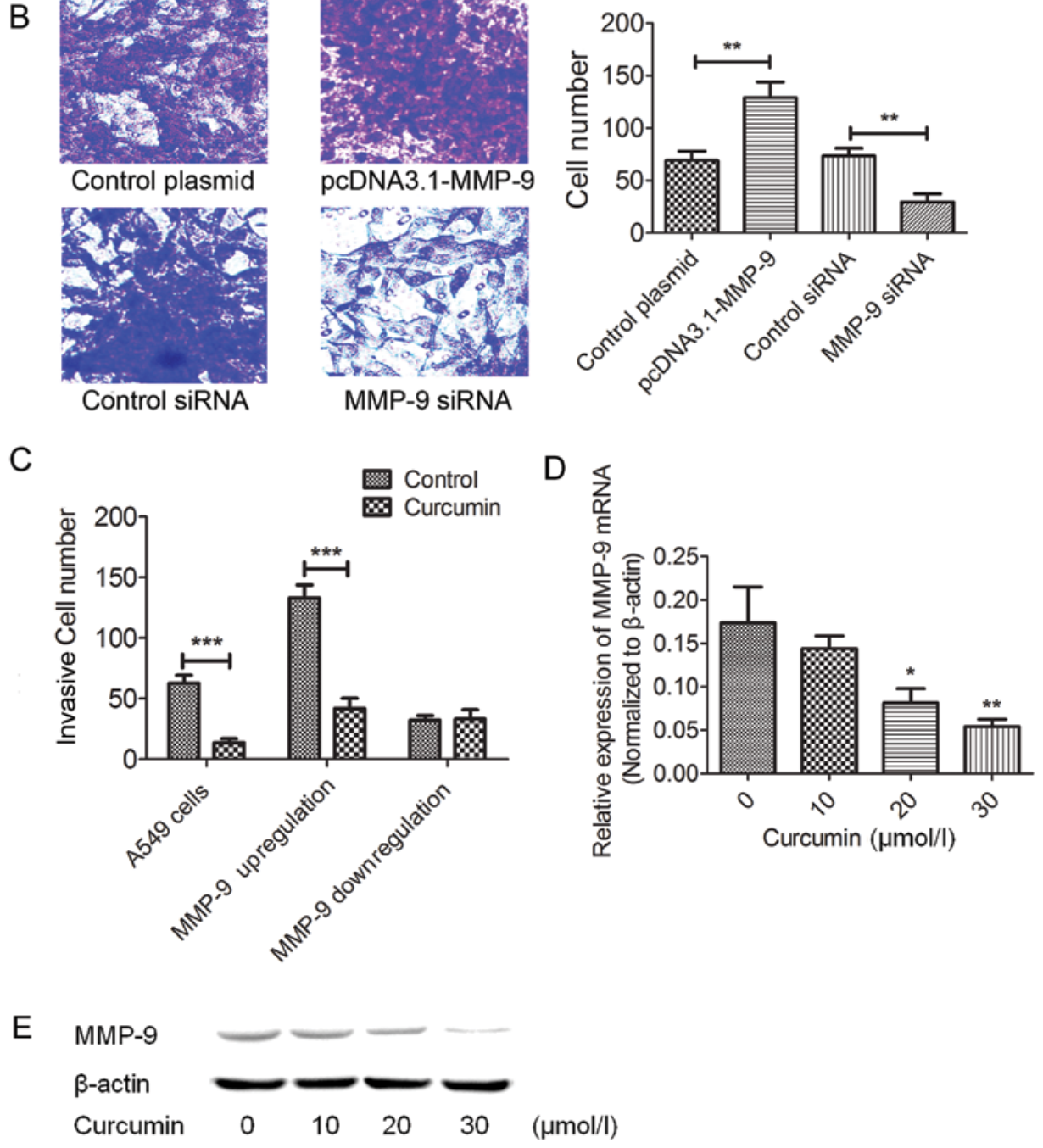

Figure 2. Curcumin inhibits the invasion of A549 cells by suppressing expression of MMP-9. (A) Regulation of MMP-9 expression by cDNA plasmid and siRNA in the A549 cells was detected by western blot analysis; ${ }^{*} \mathrm{P}<0.05,{ }^{* * *} \mathrm{P}<0.001$. (B) The effect of the regulation of MMP-9 on cell invasion in the A549 cells was determined by Transwell assay. The results are from three independent experiments; ${ }^{* *} \mathrm{P}<0.01$. (C) The effects of the upregulation and downregulation of MMP-9 on cell invasion inhibited by curcumin $(30 \mu \mathrm{M})$ in the A549 cells (conducted 48-h post-transfection). The results are from three independent experiments; ${ }^{* * *} \mathrm{P}<0.001$. (D and E) A549 cells were treated with the indicated concentrations of curcumin. The expression of mRNA (D) and protein (E) of MMP-9 was detected by real-time PCR and western blot analysis; ${ }^{*} \mathrm{P}<0.05,{ }^{* *} \mathrm{P}<0.01$. MMP, matrix metalloproteinase.

Curcumin inhibits activation of the PKCa/Nox-2/ROS/ ATF-2 pathway in A549 cells. Western blot analyses were used to assess the expression of PKC $\alpha$, Nox-2 and ATF-2 in the A549 cells after treatment with curcumin. As shown in Fig. 6A, curcumin significantly inhibited the expression of $\mathrm{PKC} \alpha, \mathrm{P} 47^{\mathrm{phox}}$ and Nox-2 in a dose-dependent manner without affecting the protein levels of ATF-2. However, phosphorylated ATF- 2 was markedly reduced by curcumin, suggesting the potential role of curcumin in suppressing the activation of ATF-2. We also detected the intracellular ROS generation in the A549 cells by DCFH-DA fluorescence which was determined by flow cytometry. As shown in Fig. 6B, after 

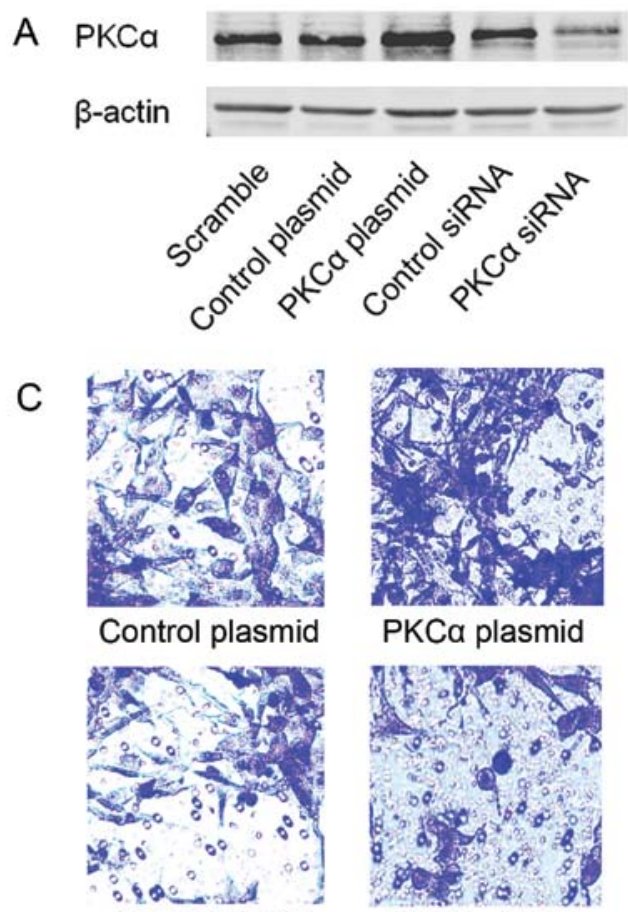

Control siRNA

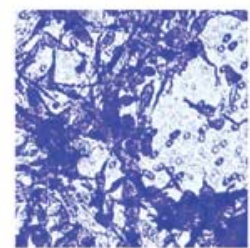

PKCa plasmid

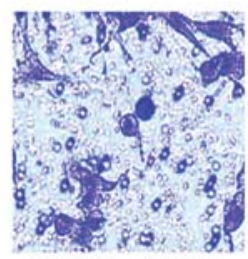

PKCa siRNA
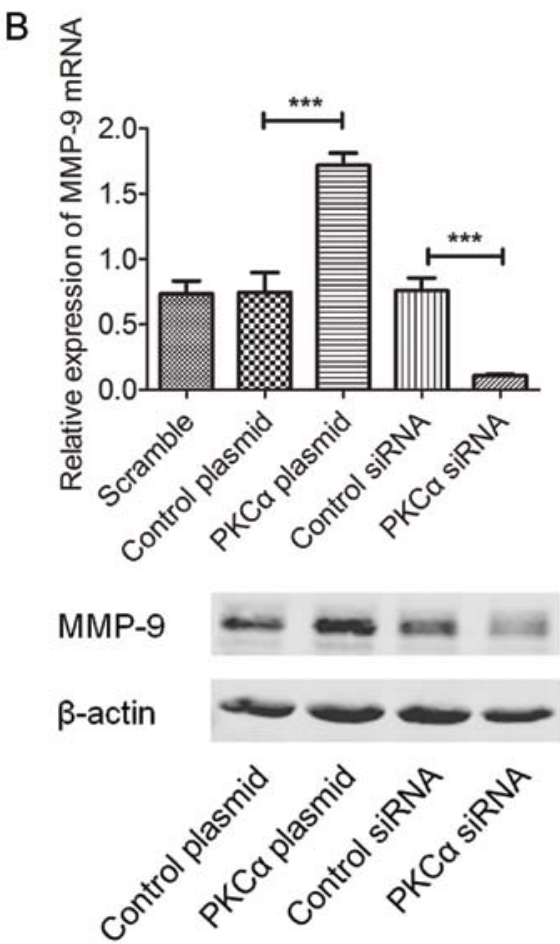

Figure 3. PKC $\alpha$ is involved in expression of MMP-9 and cell invasion in A549 cells. (A) Regulation of PKC $\alpha$ expression by cDNA plasmid and siRNA in the A549 cells was detected by western blot analysis. (B) The effects of upregulation and downregulation of PKC $\alpha$ on expression of MMP-9 in the A549 cells were assessed by real-time PCR and western blot analysis; ${ }^{* * *} \mathrm{P}<0.001$. (C) The effects of upregulation and downregulation of PKC $\alpha$ on cell invasion of the A549 cells were assessed by Transwell assay. PKC $\alpha$, protein kinase $\mathrm{C} \alpha$; MMP, matrix metalloproteinase.

A

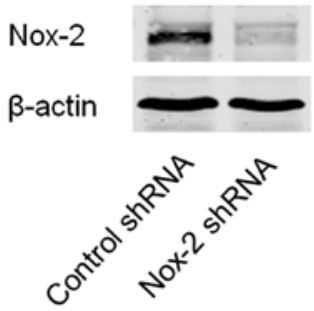

C

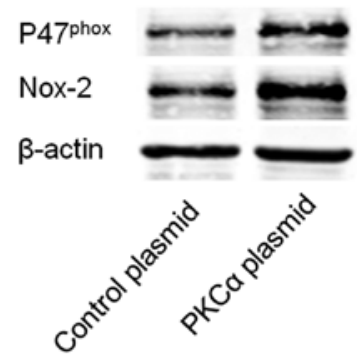

B

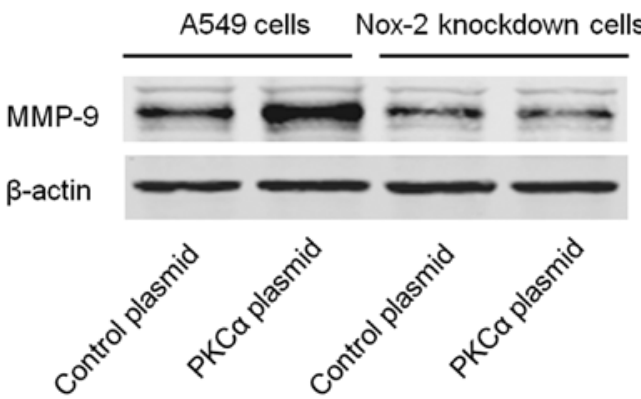

Figure 4. PKC $\alpha$-induced expression of MMP-9 is dependent on Nox-2. (A) Specific downregulation of Nox-2 by shRNA. (B) The effects of the upregulation of PKC $\alpha$ on expression of MMP-9 in the control and Nox-2-knockdown A549 cells. (C) Upregulation of PKC $\alpha$-induced expression of P47 $7^{\text {phox }}$ and Nox-2 in the A549 cells. PKC $\alpha$, protein kinase C $\alpha$; MMP, matrix metalloproteinase; Nox-2, NADPH oxidase-2.

incubation with curcumin, the ROS production was significantly decreased. Similar results of decreased ROS generation were also observed in the PKC $\alpha$ and Nox-2 siRNA-treated A549 cells.
A
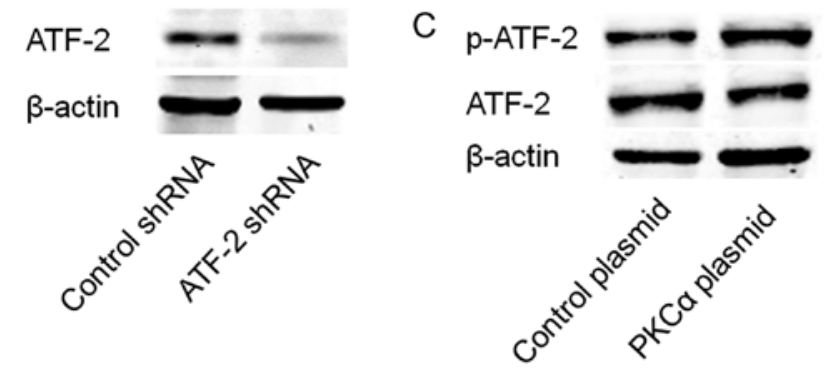

B

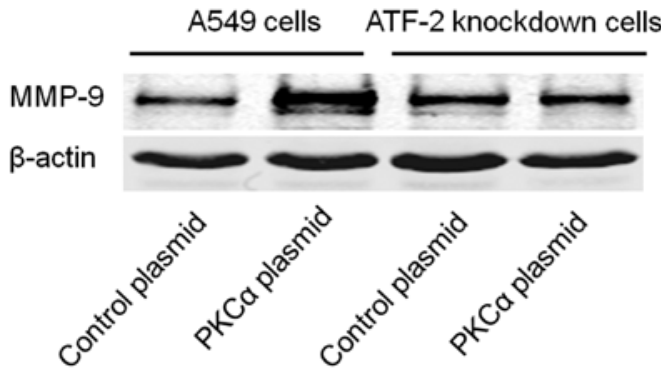

Figure 5. PKC $\alpha$-induced expression of MMP-9 is ATF-2-dependent. (A) Specific downregulation of ATF-2 by shRNA. (B) The effects of upregulation of PKC $\alpha$ on expression of MMP-9 in the control and ATF-2-knockdown A549 cells. (C) Upregulation of PKC $\alpha$ induced the phosphorylation of ATF-2. PKC $\alpha$, protein kinase $\mathrm{C} \alpha$; MMP, matrix metalloproteinase; ATF-2, activating transcription factor- 2 .

\section{Discussion}

Various types of natural therapeutic drugs such as ginsenoside, baicalein and sophocarpine exhibit anticancer effects in 

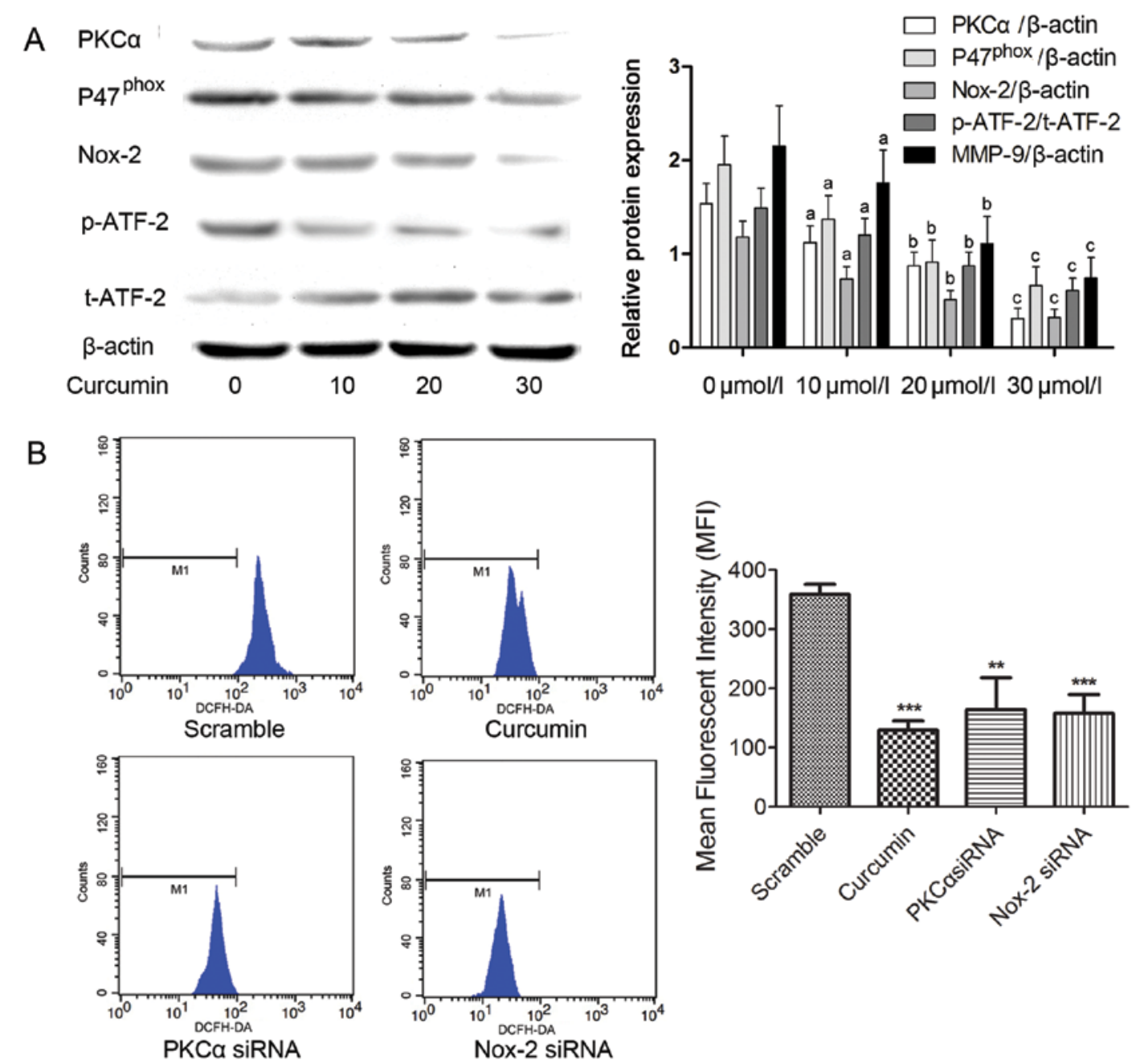

Figure 6. Curcumin inhibits the activation of the PKC $\alpha$ /Nox-2/ROS/ATF-2 signaling pathway in the A549 cells. (A) A549 cells were treated with the indicated concentrations of curcumin. The expression of PKCa, P47 ${ }^{\text {phox }}$, Nox-2, phosphorylated (p)-ATF-2 and total (t)-ATF-2 were detected by western blot analysis The columns indicate the relative protein expression of PKC $\alpha$, P47 $7^{\text {phox }}$, (p)-ATF-2 and (t)-ATF-2 in the A549 cells treated with curcumin at the indicated concentrations, respectively. (B) The effects of curcumin ( $30 \mu \mathrm{mol} / 1)$, PKC $\alpha$ siRNA and Nox-2 siRNA on intracellular ROS levels in the A549 cells were assessed by detection of DCFH-DA using a flow cytometer. The columns indicate the mean fluorescent intensity of detected DCFH-DA for each treatment expressed as mean \pm SD of three independent experiments; ${ }^{* *} \mathrm{P}<0.01,{ }^{* * *} \mathrm{P}<0.001$. PKC $\alpha$, protein kinase C $\alpha$; ATF-2, activating transcription factor-2; Nox-2, NADPH oxidase-2; ROS, reactive oxygen species.

many human types of cancer such as hepatic, breast, cervical and lung cancer (23-25). The therapeutic mechanisms of these natural drugs are extremely complicated, and involve effects on apoptotic-related genes, adhesive molecules and transcription factors (26). In the present study, we demonstrated that the overexpression of MMP-9 which is associated with the invasive ability of lung cancer A549 cells was mediated by the PKC $\alpha /$ Nox-2/ATF-2 signaling pathway. Furthermore, we revealed that the anti-invasive therapeutic effect of curcumin was based on modulating this pathway.

MMPs are a large family of proteases which play crucial roles in the development and progression of cancer (27). As a member of the MMPs, MMP-9 is indispensible in tumorigenesis, invasion and metastasis based on its collagenase activity in ECM degradation (28). Loss of ECM of blood and lymphatic vessel walls prompts cancer cells to spread to organs by invading into blood and lymphatic systems. According to a previous study, the nuclear transcription factor AP-1 regulates the expression of MMP-9 directly by binding to the AP-1 site of the promoter region of the MMP-9 gene (29). This binding process is believed to depend on ATF-2 which facilitates AP-1 binding to the MMP-9 promoter after forming a heterodimer structure based on its activation by phosphorylation (30). It was reported that the phosphorylation of ATF-2 is induced by excessive intracellular ROS generation (14).

Under many pathological conditions, Nox is the major source of ROS production (31). Nox-2, also regarded as gp91 $1^{\text {phox }}$, is a prototype NADPH oxidase. As a transmembrane protein, it transfers electrons through a chain reaction to electron donors to form ROS inside cells. The activation of Nox-2 is initiated by phosphorylation of P47phox the 'organizer subunit', which recruits P67 $7^{\text {phox }}$ and $\mathrm{P} 40^{\text {phox }}$ to form the activated Nox-2 complex $(32,33)$. It has been suggested that the phosphorylation of $\mathrm{P} 47^{\text {phox }}$ is conducted by PKC $\alpha$ in neutrophils (34). Thus, the above described molecules form a signaling pathway which could be referred as PKC $\alpha$ stimulated Nox-2-dependent ROS-activated ATF-2-induced MMP-9 expression. 
In the present study, RNA interference technique was employed to confirm the existence of this pathway in lung cancer cells. Knockdown of both PKC $\alpha$ and Nox-2 not only reduced the production of intracellular production of ROS, but also markedly impaired MMP-9 expression in the lung cancer A549 cells. As a result, PKC $\alpha$ and Nox-2 knockdown suppressed the invasive ability of A549 cells. These results indicate that $\mathrm{PKC} \alpha / \mathrm{Nox}-2 / \mathrm{ROS} / \mathrm{ATF}-2 / \mathrm{MMP}-9$ signaling is activated to induce invasion.

With a long history, from ancient times, curcumin has been used as a herbal remedy in traditional Chinese and Indian medicine in the treatment of numerous diseases (35). In recent decades, studies have identified numerous therapeutic activities including antioxidant, antidiabetic, anti-inflammatory and anticancer for this plant polyphenol, which is extracted from the roots of the spice turmeric (Curcuma longa L.) $(36,37)$. Curcumin exerts its inhibitory effects on the invasion and metastasis of many human cancers which are responsible for malignant tumor-related mortality. Several mechanisms of the effects of curcumin have been described in previous studies by investigating MMPs (38), adhesion molecules (39), angiogenesis (40) and the tumor microenvironment (41). We observed that the invasive ability of the A549 cells was significantly inhibited by curcumin treatment via reduced MMP- 9 expression. The results also indicated that the MMP-9 reduction was due to curcumin's effect of downregulating the PKC $\alpha /$ Nox-2/ROS/ ATF-2 signaling pathway in lung cancer A549 cells.

The PKC $\alpha /$ Nox-2/ROS/ATF-2/MMP-9 signaling pathway is activated in lung cancer A549 cells to maintain invasiveness. Curcumin impairs cell invasion by modulating the PKC $\alpha$ /Nox-2/ROS/ATF-2 signaling pathway to reduce MMP-9 expression in the A549 cells.

\section{References}

1. Minami-Shimmyo Y, Ohe Y, Yamamoto S, Sumi M, Nokihara H, Horinouchi H, Yamamoto N, Sekine I, Kubota K and Tamura T: Risk factors for treatment-related death associated with chemotherapy and thoracic radiotherapy for lung cancer. J Thorac Oncol 7: 177-182, 2012.

2. Hung JJ, Jeng WJ, Hsu WH, Chou TY, Huang BS and Wu YC: Predictors of death, local recurrence, and distant metastasis in completely resected pathological stage-I non-small-cell lung cancer. J Thorac Oncol 7: 1115-1123, 2012.

3. Schiavina R, Borghesi M, Brunocilla E, Manferrari F, Fiorentino M, Vagnoni V, Baccos A, Pultrone CV, Rocca GC, Rizzi S, et al: Differing risk of cancer death among patients with lymph node metastasis after radical prostatectomy and pelvic lymph node dissection: Identification of risk categories according to number of positive nodes and Gleason score. BJU Int 111: 1237-1244, 2013.

4. Mizutani K, Kofuji K and Shirouzu K: The significance of MMP-1 and MMP-2 in peritoneal disseminated metastasis of gastric cancer. Surg Today 30: 614-621, 2000.

5. Zhang HM, Han YJ, Zhao WB, Hu LJ, Fei YT and Tu Y: Effects of scalp acupuncture on expression of hippocampal MMP-9 in cerebral ischemia injury rats. Zhen Ci Yan Jiu 36: 193-198, 2011 (In Chinese)

6. Kim HJ, Fillmore HL, Reeves TM and Phillips LL: Elevation of hippocampal MMP-3 expression and activity during trauma-induced synaptogenesis. Exp Neurol 192: 60-72, 2005.

7. Sun C, Wang Q, Zhou H, Yu S, Simard AR, Kang C, Li Y, Kong Y, An T, Wen Y, et al: Antisense MMP-9 RNA inhibits malignant glioma cell growth in vitro and in vivo. Neurosci Bull 29: 83-93, 2013.
8. Lin ZM, Zhao JX, Duan XN, Zhang LB, Ye JM, Xu L and Liu YH: Effects of tissue factor, PAR-2 and MMP-9 expression on human breast cancer cell line MCF-7 invasion. Asian Pac J Cancer Prev 15: 643-646, 2014.

9. Oshima T, Kunisaki C, Yoshihara K, Yamada R, Yamamoto N, Sato T, Makino H, Yamagishi S, Nagano Y, Fujii S, et al: Clinicopathological significance of the gene expression of matrix metalloproteinases and reversion-inducing cysteine-rich protein with Kazal motifs in patients with colorectal cancer: MMP-2 gene expression is a useful predictor of liver metastasis from colorectal cancer. Oncol Rep 19: 1285-1291, 2008.

10. Lee LY, Wu CM, Wang CC, Yu JS, Liang Y, Huang KH, Lo CH and Hwang TL: Expression of matrix metalloproteinases MMP-2 and MMP-9 in gastric cancer and their relation to claudin-4 expression. Histol Histopathol 23: 515-521, 2008.

11. Park SY, Kim YH, Kim Y and Lee SJ: Frondoside A has an anti-invasive effect by inhibiting TPA-induced MMP-9 activation via NF- $\kappa$ B and AP-1 signaling in human breast cancer cells. Int J Oncol 41: 933-940, 2012.

12. Kim ES, Sohn YW and Moon A: TGF-beta-induced transcriptional activation of MMP-2 is mediated by activating transcription factor (ATF)2 in human breast epithelial cells. Cancer Lett 252: 147-156, 2007.

13. Hsieh HL, Lin CC, Shih RH, Hsiao LD and Yang CM: NADPH oxidase-mediated redox signal contributes to lipoteichoic acid-induced MMP-9 upregulation in brain astrocytes. J Neuroinflammation 9: 110, 2012.

14. Liu WH and Chang LS: Arachidonic acid induces Fas and FasL upregulation in human leukemia U937 cells via $\mathrm{Ca}^{2+} /$ ROS-mediated suppression of ERK/c-Fos pathway and activation of p38 MAPK/ATF-2 pathway. Toxicol Lett 191: 140-148, 2009.

15. Ji JL, Huang XF and Zhu HL: Curcumin and its formulations: Potential anti-cancer agents. Anticancer Agents Med Chem 12: 210-218, 2012.

16. Chen CC, Sureshbabul M, Chen HW, Lin YS, Lee JY, Hong QS Yang YC and Yu SL: Curcumin suppresses metastasis via Sp-1, FAK inhibition, and E-cadherin upregulation in colorectal cancer. Evid Based Complement Alternat Med 2013: 541695, 2013.

17. Chen HW, Lee JY, Huang JY, Wang CC, Chen WJ, Su SF, Huang CW, Ho CC, Chen JJ, Tsai MF, et al: Curcumin inhibits lung cancer cell invasion and metastasis through the tumor suppressor HLJ1. Cancer Res 68: 7428-7438, 2008.

18. Chan WH, Wu HJ and Hsuuw YD: Curcumin inhibits ROS formation and apoptosis in methylglyoxal-treated human hepatoma G2 cells. Ann NY Acad Sci 1042: 372-378, 2005.

19. Carbone F, Camillo Teixeira P, Braunersreuther V, Mach F, Vuilleumier N and Montecucco F: Pathophysiology and treatments of oxidative injury in ischemic stroke: Focus on the phagocytic NADPH oxidase 2. Antioxid Redox Signal: Apr 22, 2014 (Epub ahead of print). doi:10.1089/ars.2013.5778.

20. Makino J, Kamiya T, Hara H and Adachi T: TPA induces the expression of EC-SOD in human monocytic THP-1 cells: Involvement of PKC, MEK/ERK and NOX-derived ROS. Free Radic Res 46: 637-644, 2012.

21. Soetikno V, Watanabe K, Sari FR, Harima M, Thandavarayan RA, Veeraveedu PT, Arozal W, Sukumaran V, Lakshmanan AP, Arumugam S, et al: Curcumin attenuates diabetic nephropathy by inhibiting PKC- $\alpha$ and PKC- $\beta 1$ activity in streptozotocin-induced type I diabetic rats. Mol Nutr Food Res 55: 1655-1665, 2011.

22. Soh JW and Weinstein IB: Roles of specific isoforms of protein kinase $\mathrm{C}$ in the transcriptional control of cyclin D1 and related genes. J Biol Chem 278: 34709-34716, 2003.

23. Chen XP, Qian LL, Jiang H and Chen JH: Ginsenoside Rg3 inhibits CXCR4 expression and related migrations in a breast cancer cell line. Int J Clin Oncol 16: 519-523, 2011.

24. Chen J, Li Z, Chen AY, Ye X, Luo H, Rankin GO and Chen YC: Inhibitory effect of baicalin and baicalein on ovarian cancer cells. Int J Mol Sci 14: 6012-6025, 2013.

25. Li LQ, Li XL, Wang L, Du WJ, Guo R, Liang HH, Liu X, Liang DS, Lu YJ, Shan HL, et al: Matrine inhibits breast cancer growth via miR-21/PTEN/Akt pathway in MCF-7 cells. Cell Physiol Biochem 30: 631-641, 2012.

26. Saha SK and Khuda-Bukhsh AR: Molecular approaches towards development of purified natural products and their structurally known derivatives as efficient anti-cancer drugs: Current trends. Eur J Pharmacol 714: 239-248, 2013. 
27. Schmalfeldt B, Prechtel D, Härting K, Späthe K, Rutke S Konik E, Fridman R, Berger U, Schmitt M, Kuhn W, et al: Increased expression of matrix metalloproteinases (MMP)-2, MMP-9, and the urokinase-type plasminogen activator is associated with progression from benign to advanced ovarian cancer. Clin Cancer Res 7: 2396-2404, 2001.

28. Mehner C, Hockla A, Miller E, Ran S, Radisky DC and Radisky ES: Tumor cell-produced matrix metalloproteinase 9 (MMP-9) drives malignant progression and metastasis of basal-like triple negative breast cancer. Oncotarget 5: 2736-2749, 2014.

29. Kim HS, Kim MH, Jeong M, Hwang YS, Lim SH, Shin BA, Ahn BW and Jung YD: EGCG blocks tumor promoter-induced MMP-9 expression via suppression of MAPK and AP-1 activation in human gastric AGS cells. Anticancer Res 24: 747-753, 2004.

30. Yeh JH, Lecine P, Nunes JA, Spicuglia S, Ferrier P, Olive D and Imbert J: Novel CD28-responsive enhancer activated by CREB/ATF and AP-1 families in the human interleukin-2 receptor alpha-chain locus. Mol Cell Biol 21: 4515-4527, 2001.

31. Jendrysik MA, Vasilevsky S, Yi L, Wood A, Zhu N, Zhao Y, Koontz SM and Jackson SH: NADPH oxidase-2 derived ROS dictates murine DC cytokine-mediated cell fate decisions during CD4 T helper-cell commitment. PLoS One 6: e28198, 2011.

32. Kuo FC, Tseng YT, Wu SR, Wu MT and Lo YC: Melamine activates $\mathrm{NF}-\kappa \mathrm{B} / \mathrm{COX}-2 / \mathrm{PGE} 2$ pathway and increases NADPH oxidase-dependent ROS production in macrophages and human embryonic kidney cells. Toxicol In Vitro 27: 1603-1611, 2013.

33. Jiang Q, Zhou C, Healey S, Chu W, Kouttab N, Bi Z and Wan Y: UV radiation down-regulates Dsg-2 via Rac/NADPH oxidase-mediated generation of ROS in human lens epithelial cells. Int J Mol Med 18: 381-387, 2006.

34. Remijsen QF, Fontayne A, Verdonck F, Clynen E, Schoofs L and Willems J: The antimicrobial peptide parabutoporin competes with p47(phox) as a PKC-substrate and inhibits NADPH oxidase in human neutrophils. FEBS Lett 580: 6206-6210, 2006.
35. Anstrom DM, Zhou X, Kalk CN, Song B and Lan Q: Mosquitocidal properties of natural product compounds isolated from Chinese herbs and synthetic analogs of curcumin. J Med Entomol 49: 350-355, 2012

36. Yilmaz Savcun G, Ozkan E, Dulundu E, Topaloğlu U, Sehirli AO, Tok OE, Ercan F and Sener G: Antioxidant and anti-inflammatory effects of curcumin against hepatorenal oxidative injury in an experimental sepsis model in rats. Ulus Travma Acil Cerrahi Derg 19: 507-515, 2013.

37. Meng B, Li J and Cao H: Antioxidant and antiinflammatory activities of curcumin on diabetes mellitus and its complications. Curr Pharm Des 19: 2101-2113, 2013.

38. Mo N, Li ZQ, Li J and Cao YD: Curcumin inhibits TGF- $\beta 1$-induced MMP-9 and invasion through ERK and Smad signaling in breast cancer MDA-MB-231 cells. Asian Pac J Cancer Prev 13: 5709-5714, 2012.

39. Pan Y, Zhang X, Wang Y, Cai L, Ren L, Tang L, Wang J, Zhao Y, Wang Y, Liu Q, et al: Targeting JNK by a new curcumin analog to inhibit NF- $\mathrm{kB}$-mediated expression of cell adhesion molecules attenuates renal macrophage infiltration and injury in diabetic mice. PLoS One 8: e79084, 2013.

40. Bimonte S, Barbieri A, Palma G, Luciano A, Rea D and Arra C: Curcumin inhibits tumor growth and angiogenesis in an orthotopic mouse model of human pancreatic cancer. Biomed Res Int 2013: 810423, 2013.

41. Vishvakarma NK, Kumar A and Singh SM: Role of curcumindependent modulation of tumor microenvironment of a murine $\mathrm{T}$ cell lymphoma in altered regulation of tumor cell survival. Toxicol Appl Pharmacol 252: 298-306, 2011. 